\title{
«Menos Camboyas, Caperucita». Reflexión sobre la represión franquista, 1939-1953
}

\author{
JuLIUS RUIZ \\ Universidad de Edimburgo \\ orcid.org/0000-0002-3122-2349 \\ Presentación: 15 feb. 2020 | Aceptación: 1 abr. 2020 | Publicación: 31 oct. 2020
}

Citació recomanada: Ruiz, Julius. 2020. «"Menos Camboyas, Caperucita”. Reflexión sobre la represión franquista, 1939-1953». Dictatorships \& Democracies. Journal of History and Culture 8: 77-94. doi: https://dx.doi.org/10.7238/dd.voi8.3183

Resumen: Este artículo examina críticamente los debates actuales sobre la represión franquista tras la victoria incondicional de Francisco Franco sobre la Segunda República en 1939. Analiza la tesis de que el tratamiento del régimen a los vencidos era producto de una política de exterminio y cuestiona la validez de la frecuente afirmación de que solo Camboya tiene más fosas comunes que España. Destaca la importancia de la institucionalización de la represión a partir del invierno de 1936-1937 y concluye que, si bien el Nuevo Estado franquista estaba decidido a castigar a los anti-españoles, no hubo una política de exterminio.

Palabras clave: represión política, Guerra Civil, régimen franquista, memoria histórica

«Less Cambodia, Little Red Riding Hood». Reflection on Franco's Repression, 1939-1953

Abstract: This article critically examines the current debates on the repression following General Franco's unconditional victory over the Republic in 1939. It analyses the claim that the regime's treatment of the vanquished reflected a policy of extermination, and questions the validity of the frequent claim that Spain is second only to Cambodia in the number of mass graves. It stresses the significance of the institutionalisation of the repression in the winter of 1936-1937, and concludes that although the Francoist New State was determined to punish anti-Spaniards, it did not exterminate them.

Key words: political repression, Spanish Civil War, Franco regime, historical memory

Las portadas de los periódicos nacionales fueron muy parecidas el 2 de abril de 1939: advirtieron que con Franco no llegaba la paz, sino la victoria. Publicaron el parte oficial de guerra firmado el día anterior en Burgos por un generalísimo acatarrado: «En el día de hoy, cautivo y desarmado el ejército rojo, han alcanzado las tropas nacionales sus últimos objetivos 
militares. La guerra ha terminado». Tal y como $A B C$ proclamó desde el recién liberado Madrid, ese sábado fue «el Día de la Victoria». ${ }^{1}$ Tres semanas después, en Málaga, el caudillo explicó: «Han acabado las jornadas de la guerra; de la guerra visible, de la guerra airosa; pero el enemigo no está muerto. No hemos luchado con españoles». ${ }^{2}$ Para el jefe de Estado, la reconciliación con los vencidos sería una traición a España. Después del desfile de la victoria en Madrid el 19 de mayo con la participación de más de cien mil combatientes, Franco recordó a los españoles a través de la radio: «Lo que significa nuestra victoria lo sabéis vosotros mejor que nadie: la existencia de nuestra Patria». Luego advirtió que el 1 de abril «terminó el frente de la guerra, pero sigue la lucha en otro campo... la revolución antiespañola no se extirpa en un solo día». Y prometió un castigo a los que habían sometido a España «a un yugo extranjero y bárbaro enfangado en la charca criminal del marxismo». Un castigo que debería ser largo porque aseguraba que «el triunfo de la revolución antiespañola fue posible por la inconsciente inhibición de tantos españoles». ${ }^{3}$

Es bien sabido que la extirpación de la «revolución antiespañola» por parte de los rebeldes no empezó en 1939 sino con la rebelión militar en julio de 1936. Sin duda, el terror y la represión han sido los temas más polémicos de la Guerra Civil. Como ha escrito Javier Rodrigo, el conflicto fue una «guerra al civil».4 La retaguardia fue más peligrosa que las líneas del frente. De las más de 300.000 víctimas del conflicto, la mitad fueron civiles. En la zona republicana, unos 50.000 fascistas fueron fusilados, mientras los rebeldes eliminaron unos 100.000 rojos. ${ }^{5}$ Aunque las cifras son espeluznantes, el conflicto español no fue la única guerra civil en Europa durante el siglo xx donde el número de fusilamientos de civiles se aproximó o superó las bajas militares. En la guerra civil finlandesa de

$1 A B C$ [Madrid], 2 abr. 1939.

$2 A B C$ [Madrid], 20 abr. 1939.

$3 A B C$ [Madrid], 20 may. 1939.

4 Javier Rodrigo, «Guerra al civil. La España de 1936 y las guerras civiles europeas (1917-1949)», dentro Javier Rodrigo, coord., Políticas de la violencia. Europa, siglo XX (Zaragoza: Prensas de la Universidad de Zaragoza, 2014).

5 Stanley G. Payne, The Spanish Civil War (Cambridge: Cambridge University Press, 2012), 244245; Francisco Espinosa, coord., Violencia roja y azul. España, 1936-1950 (Barcelona: Crítica, 2010), 77-78. Santos Juliá Díaz, coord., Víctimas de la guerra civil (Madrid: Temas de Hoy, 1999), 411-412. 
1918, menos de 10.000 soldados murieron en los frentes, mientras 10.274 civiles fueron ejecutados. ${ }^{6}$ De las 108.000 bajas en la guerra civil griega de 1943-1949, 67.00o fueron de civiles. ${ }^{7}$ Tampoco es sorprendente que los contrarevolucionarios matasen a más personas que sus enemigos; los rojos finlandeses, por ejemplo, solo fueron culpables de 1.649 fusilamientos.

Resulta también evidente que, después de veinte años de la llamada proceso de la «recuperación de la memoria histórica», la historiografía sobre la represión rebelde ha superado con creces la de sus adversarios. Como dice Fernando del Rey en 2019, «por el volumen de estudios realizados, hoy existe un manifiesto desequilibrio a favor de la historia de la represión franquista». ${ }^{8}$ Los esfuerzos de historiadores como Gutmaro Gómez Bravo, Conxita Mir, Javier Rodrigo y Juan Carlos García Funes, entre muchos más, han puesto al descubierto los mecanismos represivos del primer franquismo. ${ }^{9}$

En octubre de 2019, el tema volvió a ocupar el primer plano con la exhumación de Franco del Valle de los Caídos; «la democracia española», declaró El País, «ha derribado su último tabú». ${ }^{10}$ Pero el debate actual sobre la represión rebelde parece más interesado en los primeros meses de la guerra — sin duda los meses más sangrientos- que en la posguerra. Por ejemplo, solo uno de los trece capítulos de El holocausto Español de Paul Preston — considerado por defensores de la tesis del «genocidio franquista» como el libro de referencia sobre el tema— analiza lo que pasó después de la victoria de Franco. ${ }^{11}$

6 Stanley G. Payne, La Europa revolucionaria. Las guerras civiles que marcaron el siglo XXI (Madrid: Planeta, 2011), 56 y 61.

7 Stathis N. Kayvas, The Logic of Violence in Civil War (Nueva York: Cambridge University Press, 2005), 249.

8 Fernando del Rey, Retaguardia roja. Violencia y revolución en la guerra civil española (Barcelona: Galaxia Gutenberg, 2019), 20.

9 Gutmaro Gómez Bravo, El exilio interior: cárcel y represión en la España franquista, 1939-1950 (Madrid: Taurus, 2009); Conxita Mir, Vivir es sobrevivir: justicia, orden y marginación en la Cataluña rural de posguerra (Lleida: Milenio, 200o); Javier Rodrigo, Hasta la raíz. Violencia durante la guerra civil y la dictadura franquista (Madrid: Alianza, 2008); Juan Carlos García Funes, A recoger bombas. Batallones de trabajo forzado en Castilla y León (1937-1942) (Sevilla: Foro por la Memoria de Segovia/Atrapasueños, 2016).

10 El País, 25 oct. 2019.

11 Paul Preston, El holocausto español. Odio y exterminio en la guerra civil y después (Barcelona: Debate, 2011). Antonio Mínguez Macho, «Genocidio franquista», La genealogía genocida del franquis- 
En el ámbito político dominan las referencias a los fusilamientos sin juicio y a las fosas comunes. Se ha repetido hasta la saciedad el supuesto hecho de que solo Camboya tiene más fosas comunes que España, sobre todo por parte de políticos nacionalistas y de la izquierda. En un debate parlamentario de diciembre de 2016, por ejemplo, el portavoz del Partido Nacionalista Vasco, Aitor Esteban, reprochó al gobierno de Mariano Rajoy que no cumpliese la Ley de memoria histórica de 2007 de este modo: «No hay una oficina, no hay presupuestos, hay más de 140.000 en las cunetas, es el segundo país después de Camboya con más desaparecidos». ${ }^{12}$ Parece que esta afirmación la publicó por la primera vez Miguel Ángel Rodríguez Arias, profesor del Instituto de Derecho Penal Europeo e Internacional de la Universidad de Castilla La Mancha, en agosto de 2009. ${ }^{13}$ En este artículo, Rodríguez Arias hablaba de «143.353 desaparecidos del franquismo», aunque posteriormente el autor bajó la cifra a «114.266 desapariciones forzadas» desde 17 de julio de 1936 a diciembre de 1951, que es la misma citada en el famoso auto de Baltasar Garzón de 16 de octubre de 2008 contra el franquismo. ${ }^{14}$ En todo caso, la afirmación de Rodríguez Arias ha sido criticada por muchos historiadores y no historiadores, entre ellos el escritor Arturo Pérez-Reverte, que pidió «Menos Camboyas, Caperucita» en un artículo de octubre de 2019. ${ }^{15}$ En su defensa, el abogado sostiene que «se le malinterpretó», alegando que muchos se han confundido el concepto de desapariciones forzadas con el de fosas comunes. Aquel lo «inventaron los nazis»: «Se coge a una persona y se la llevan, como decía el mariscal Wilhelm Keitel, al Nacht und Nebel, noche y niebla. Esa persona la eliminan y la hacen desaparecer, habitualmente en una cuneta o en una fosa». ${ }^{16}$

\footnotetext{
mo. Violencia, memoria e impunidad (Madrid: Abada, 2014).

12 La Vanguardia, 21 dic. 2016.

13 Salvador López, «Seguimos siendo el segundo país del mundo en cifras de desaparecidos, tan sólo por detrás de la Camboya de Pol Pot», entrevista a Miguel Ángel Rodríguez Arias, Rebelión, 30 ag. 2009, http://www.rebelion.org/noticia.php?id=90703.

14 Baltasar Garzón, auto de 16 de octubre de 2008, Administración de Justicia, Madrid, http:// www.latinreporters.com/espagneGarzonFrancoLorca16102008M.pdf. Rodríguez Arias rectificó en El Confidencial las cifras que había dado el 6 de noviembre de 2019.

15 Arturo Pérez-Reverte, «Menos Camboyas, Caperucita», XLSemanal, 13 oct. 2019, https://www. xlsemanal.com/firmas/20191013/perez-reverte-menos-camboyas-caperucita.html.

16 El Confidencial, 6 nov. 2019.
} 
Dejando de lado consideraciones morales sobre la validez de establecer rankings de sufrimiento, la tesis de Rodríguez Arias es problemática por varias razones. En primer lugar, la mayoría de los detenidos bajo el decreto alemán Nacht und Nebel fueron deportados a Alemania, donde muchos fueron juzgados por el Tribunal del Pueblo (Volksgerichtshof); no es conocido el número de los deportados, pero es indudable que muchos murieron en las cárceles y campos de concentración nazis, y no en una cuneta. ${ }^{17}$ Más importante para la cuestión que nos ocupa, la cifra de 114.266 desapariciones forzadas es poco fiable porque está basada en informes recopilados por las asociaciones de memoria histórica, y no en investigaciones de historiadores profesionales..$^{18}$ De hecho, la visión de la represión rebelde defendida por Rodríguez Arias ignora por completo los resultados fundamentales de más de cuarenta años de estudios locales y provinciales.

Por esa razón, hay que volver a El holocausto Español de Preston. Uno de sus argumentos más interesantes (y quizás olvidado por la polémica sobre el título) es su conclusión sobre el número de víctimas de la posguerra. En su apéndice gráfico que señala los muertos por regiones, Preston concluye que se fusilaron unos 20.000 republicanos. ${ }^{19}$ Esto es muy significativo. Hace veinte años, muchos historiadores, sobre todo anglosajones, hablaban de 200.000. ${ }^{20}$ Es decir, la cifra actualizada representa el diez por ciento de la anterior. Esto subraya el hecho de que la investigación ha demostrado que la cronología es una de las claves para entender la represión del bando rebelde. En otras palabras, la gran mayoría de víctimas se fusilaron durante la guerra misma, o para ser más exactos, en los primeros meses de guerra antes de la proclamación de Franco como el jefe del Estado en octubre de 1936. Julián Casanova ha demostrado que más de cincuenta por ciento de todas las ejecuciones antes de la muerte

17 Ian C. B. Dear y Michael R. D. Foot, dir., The Oxford Companion to the Second World War (Oxford: Oxford University Press, 2001).

18 Sobre las deficiencias del auto de Garzón, véase Julius Ruiz, «¿El genocidio español? Reflexiones sobre el auto de Garzón», Noticiero de las ideas 37 (2009), 6o-67.

19 Preston, El holocausto español, 817-823.

20 Véase, por ejemplo, Michael Richards, A Time of Silence. Civil War and the Culture of Repression in Franco's Spain, 1936-1945 (Cambridge: Cambridge University Press, 1998), 11. 
de Franco en noviembre de 1975 tuvieron lugar entre julio y octubre de $1936 .{ }^{21}$ Los fusilamientos fueron más elevados en términos absolutos y relativos en las zonas agrícolas conquistadas al principio de la guerra que en los centros urbanos ocupados en 1939, independientemente de factores como el número de habitantes o la pujanza de las organizaciones del Frente Popular. Con la excepción importante de Málaga (7.471 víctimas), las provincias con más de 6.000 muertos habían sido total o parcialmente ocupadas por los rebeldes en 1936. Están en Andalucía (Sevilla, 12.507; Córdoba, 9.579; Huelva, 6.019), Extremadura (Badajoz, 8.914) y Aragón (Zaragoza, 6.00o). Las provincias ocupadas por los franquistas en 1939 están muy por debajo en el ranking, entre ellas Madrid (3.204), Valencia (3.128) y Barcelona (1.716). ${ }^{22}$

¿Cómo se pueden explicar las diferencias entre provincias? No hay duda de que el discurso franquista no cambió sustancialmente durante los años de guerra y los primeros años de posguerra. Los llamamientos a la depuración o a la purificación de España fueron una constante. El propio Franco le dijo al periodista Manuel Aznar en enero de 1939 que era imposible «devolver a la sociedad, o como si dijéramos, a la circulación social, elementos dañados, pervertidos, envenenados políticamente y moralmente» sin antes «tomar precauciones» pues representarían «un peligro de corrupción y de contagio para todos, al par que el fracaso histórico de una victoria alcanzada a costa de tanto sacrificio». ${ }^{23}$ Casi cinco años después, en diciembre de 1943, el ministro de Justicia Eduardo Aunós, en el prólogo del avance de la Causa General, la investigación franquista de los «crímenes rojos», arremetió contra «las masas enfebrecidas por la ola de crimen y de sangre que abrió el marxismo y sus aliados».. ${ }^{24}$ El declive de fusilamientos, tanto en términos absolutos como relativos, en modo alguno refleja una política de reconciliación.

En realidad, algunos estudios provinciales indican una relación entre la institucionalización de la represión y el descenso de ejecuciones. Este proceso creó antes del fin de la guerra un entramado burocrático dedica-

21 Juliá, coord., Victimas de la guerra civil, 64-65.

22 Espinosa, coord., Violencia, 77; Preston, Holocausto, 817-823.

23 Informaciones, 11 abr. 1939.

24 Ministerio de Justicia, «Causa general: la dominación roja en España» (Madrid, 1943), 6.

DICTATORSHIPS \& DEMOCRACIES 8 (2020) · E-ISSN: 2564-8829 - PUNCTUM, UNIVERSITAT OBERTA DE CATALUNYA \& FUNDACIÓ CARLES PII SUNYER 
do al castigo de los vencidos. Los procesamientos judiciales estaban basados en una ficción legal: los republicanos eran los culpables de la guerra. Como Ramón Serrano Suñer admitió en sus memorias, fue «la justicia al revés». ${ }^{25}$ En el centro estaban los consejos de guerra que condenaron los vencidos por el supuesto delito de rebelión militar; pero también había los tribunales de Responsabilidades Políticas, que incautaron los bienes de los derrotados, las depuraciones sociolaborales, y a partir de marzo de 1940, el Tribunal Especial para la Represión de la Masonería y el Comunismo (TERMC), dedicado al castigo del llamado «contubernio judeo-masónico-comunista». En paralelo, el régimen franquista prometía la redención de los presos, o sea la conversión de rojos a españoles a través del trabajo forzoso. El resultado de todo este proceso represivo masivo es claro: cientos de miles de procesados y condenados. Sin embargo, el régimen franquista también tomó una serie de decisiones destinadas a liquidar buena parte de aquel proceso represor durante los años cuarenta. Esto no supone, por supuesto, que no hubiera represalias después o que la división entre vencedores y vencidos hubiese desaparecido. De hecho continuó la persecución despiadada de la oposición antifranquista, sobre todo de los maquis. ${ }^{26}$ La derrota de la lucha guerrillera y los acuerdos con el Vaticano y los Estados Unidos en 1953, que supusieron el fin del aislamiento internacional del régimen después de 1945, no marcaron un antes y un después en la división ideológica de España entre los buenos y los malos. ${ }^{27}$ Se mantuvieron los ritos de la victoria y el culto a los llamados «mártires» sin solución de continuidad; las delirantes denuncias de Franco contra «una conspiración masónica izquierdista en la clase política, en contubernio con la subversión comunista-terrorista en lo social» en su

25 Ramón Serrano Suñer, Entre el silencio y la propaganda, la historia como fue. Memorias (Barcelona: Planeta, 1977), 245.

26 En relación a la persecución de la oposición antifranquista en los años cuarenta sigue siendo fundamental el libro de Hartmut Heine, La oposición política al franquismo (Barcelona: Crítica, 1983). Hay muchos estudios sobre los maquis, por ejemplo, el de Secundino Serrano, Maquis. Historia de la guerrilla antifranquista. Madrid: Temas de Hoy, 2001), o el de Jorge Marco, Guerrilleros y vecinos en armas. Identidades y culturas de la resistencia antifranquista (Granada: Comares, 2012).

27 Javier Rodrigo, Cruzada, paz, memoria. La Guerra Civil en sus relatos (Granada: Comares, 2013), 53-98. 
último discurso público el 1 de octubre de 1975 demuestran que el caudillo defendió su cruzada contra los enemigos de la patria hasta el final. ${ }^{28}$

\section{II}

Si es difícil establecer una línea divisoria en la represión de posguerra, es imposible analizarla sin hacer referencia a los acontecimientos de 1936. No cabe duda de que los rebeldes estaban dispuestos a todo para garantizar el éxito de la rebelión. La primera instrucción reservada de su director general Mola en mayo no deja dudas al respecto; en ella advertia que «la acción ha de ser en extremo violenta para reducir lo antes posible al enemigo» y que «desde luego serán encarcelados todos los directivos de los partidos políticos, sociedades o sindicatos no afectos al Movimiento, aplicándoles castigos ejemplares a dichos individuos». ${ }^{29}$ Son bien conocidos los discursos y exacerbación de la violencia de los dirigentes de la rebelión en el verano de 1936, y Baltasar Garzón reproduce algunos en su auto de 2008, como una alocución en Radio Sevilla del general Queipo de Llano que decía: «Yo os autorizo a matar, como a un perro, a cualquiera que se atreva a ejercer coacción ante vosotros: que si lo hiciereis así, quedaréis exentos de toda responsabilidad $» .^{30}$ Las cuantiosas matanzas de los primeros meses de guerra fueron selectivas, dirigidas contra militares y policías leales al Gobierno republicano, dirigentes y activistas de todas las organizaciones del Frente Popular, y también contra republicanos de izquierda, librepensadores y cualquier otro asociado con la obra secular de la República. ${ }^{31}$

Para muchos historiadores, la conclusión es innegable. Como Secundino Serrano escribió en 2008: «En su conquista del país, los rebeldes se vieron obligados a pacificar la retaguardia y, como no disponían de las fuerzas necesarias para ello, utilizaron la violencia como parte de la estrategia militar. La oleada de terror que sacudió a las provincias conforme triun-

28 ABC [Madrid], 2 oct. 1975.

29 Alberto Reig Tapia, Ideología e historia: sobre la represión franquista y la Guerra Civil (Madrid: Akal, 1984), 146.

30 Garzón, auto de 16 de octubre de 2008, 12.

31 Preston, Holocausto, capítulos 5-6.

DICTATORSHIPS \& DEMOCRACIES 8 (2020) · E-ISSN: 2564-8829 - PUNCTUM, UNIVERSITAT OBERTA DE CATALUNYA \& FUNDACIÓ CARLES PII SUNYER 
faba la sublevación seguía esas pautas: impedir la reacción de los vencidos, invitarlos a la rendición sin condiciones. En la mentalidad de los jefes sublevados no cabía negociación alguna. El corolario parecía evidente: no sólo era una guerra civil, sino también un programa de exterminio».32

¿Pero existía realmente ese programa? En teoría, la España rebelde estaba bajo el estado de guerra, declarado en toda la zona el 28 de julio de $1936 .{ }^{33}$ En realidad, y a pesar de esa declaración, la gran mayoría de los asesinatos fueron extrajudiciales, perpetrados por civiles como falangistas y carlistas con el consentimiento de las autoridades militares. ${ }^{34} \mathrm{Du}$ rante el verano sangriento de 1936, en general los tribunales militares solo condenaron a militares y políticos republicanos destacados. ${ }^{35}$ En Sevilla, por ejemplo, por lo menos 433 personas fueron fusiladas antes del primer consejo de guerra en agosto. ${ }^{36} \mathrm{El}$ primer inculpado fue el general Miguel Campins, comandante militar de Granada. Su ejecución dos días más tarde refleja la fragmentación de poder en la zona rebelde: Queipo de Llano, el llamado virrey de Andalucía, rechazó un intento de Franco de salvar la vida de su amigo. ${ }^{37}$

El terror de 1936 no es una violencia espontánea, pero tampoco es una represión institucionalizada. De hecho, el desarrollo lento de la institucionalización de la justicia militar solo empezó en el invierno de 1936-1937 como consecuencia de la tendencia a centralizar el poder en las manos de Franco después de su investidura como comandante en jefe del Ejército alzado y como jefe de Estado, y de la creación de una nueva administración -la Junta Técnica del Estado- en octubre..$^{38}$ Es indicativo, también, del optimismo general existente entre los rebeldes sobre la marcha de la guerra después de la caída de Toledo a finales de septiembre, cuando

32 Secundino Serrano, «Génesis del conflicto: La represión de los huidos. La Federación Guerrillera de León-Galicia», dentro José Aróstegui y Jorge Marco, coord., El último frente. Resistencia armada antifranquista en España 1939-1952 (Madrid: Catarata, 2008), 101-102.

33 Boletín Oficial de la Junta de Defensa Nacional de España, 30 jul. 1936.

34 Juliá, coord., Victimas, 81-116.

35 Véase, por ejemplo, Juan Ortiz Villalba, Del golpe militar a la guerra civil: Sevilla 1936 (Córdoba: Vistalegre, 1998).

36 Alfonso Braojos et al., Sevilla, 36: sublevación fascista y represión (Sevilla: Muñoz Moya y Montraveta editores, 1990), 252-253

37 Ortiz, Del golpe militar a la guerra civil, 190-195.

38 Boletín Oficial del Estado, 2 oct. 1936. 
la victoria definitiva era considerada inminente. En noviembre de 1936 establecieron por decreto un organismo jurídico militar con el nombre revelador de «Auditoría del Ejército de Ocupación» para aplicar la justicia militar en el Madrid liberado. ${ }^{39}$ Después del fracaso de la ofensiva franquista sobre la capital, se disolvieron las esperanzas de una victoria rápida y se ordenó por decreto en enero de 1937 la expansión masiva de la justicia militar en la zona franquista..$^{\circ}$

Eso no significa que podamos marcar una clara línea divisoria entre represión arbitraria y legal en 1937. La construcción del Nuevo Estado fue gradual: el primer gobierno franquista no se estableció hasta enero de $1938 .{ }^{41}$ Se pueden ver los límites del proceso de la institucionalización de la justicia militar en Málaga después de la toma de la ciudad en febrero de 1937: la debilidad de las autoridades centrales en la implementación de la justicia contribuyó a una represión brutal, con más de 3.000 víctimas en los diez primeros meses de la ocupación. ${ }^{42}$ No obstante, es indudable que el invierno de 1936-1937 es el punto de inflexión en el número de fusilamientos en las provincias ocupadas al principio de la guerra; solo entre el diez y el veinte por ciento tuvo lugar después de diciembre de 1936.43

También parece indudable que la gran mayoría de los fusilamientos de posguerra fueron consecuencia de sentencias de muerte por rebelión militar dictadas por los consejos de guerra. ${ }^{44}$ Hay que subrayar de nuevo que el fin de la guerra no significó ninguna novedad: el estado de guerra perduró en España hasta abril de $1948 .{ }^{45}$ Las fuerzas policiales que entraron en las ciudades antes republicanas fueron llamadas «columnas de orden y ocupación», y los consejos de guerra en Madrid actuaron bajo la

39 Boletín Oficial del Estado, 5 nov. 1936.

40 Boletín Oficial del Estado, 26 en. 1937.

41 Stanley G. Payne, The Franco Regime, 1936-1975 (Madison: University of Wisconsin Press, 1987), 163-196.

42 Para la represión en Málaga, véanse, por ejemplo, las obras de Antonio Nadal, Guerra civil en Málaga (Málaga: Arguval, 1984), y de Encarnación Barranquero Texeira, Málaga entre la guerra y la posguerra (Málaga: Arguval, 1994).

43 Juliá, coord., Victimas, 65.

44 Julius Ruiz, «A Spanish Genocide? Reflections on the post-war Francoist repression», Contemporary European History, vol. 14 (mayo 2005), 179.

45 Manuel Ballbé, Orden público y militarismo en la España constitucional (1812-1983), (Madrid: Alianza, 1985), 409 . 
jurisdicción de la Auditoría del Ejército de Ocupación. Por lo tanto, el régimen franquista trató su nuevo territorio como si fuera tierra extranjera. En especial, Madrid, como reconocía el $A B C$ en marzo de 1940 con motivo del primer aniversario de la toma la ciudad, «planteó un gigantesco problema $»{ }^{46}$ La capital de España había resistido a los ataques franquistas durante más de dos años y su lucha había sido celebrada por antifascistas de todo el mundo. En mayo de 1939, Serrano Suñer, el ministro de Interior, proclamó: «Hay que hacer un Madrid nuevo... Un Madrid donde nunca más puedan cometerse las vilezas que aquí se cometieron en el dominio rojo». El cuñado de Franco pidió ayuda «para que todos podamos acabar con la españolería trágica del Madrid decadente y castizo, aunque hayan de desaparecer la Puerta del Sol y ese edificio de Gobernación, que es un caldo de cultivo de los peores gérmenes políticos».47 Así pues, uno de los dilemas a los que se enfrentaba el régimen de Franco en los primeros meses de paz era el de si una ciudad como Madrid, con semejantes connotaciones rojas, debía continuar siendo la capital de España. A lo largo de 1939, en los altos círculos gubernamentales se barajaron y debatieron posibles candidatas alternativas..$^{8}$ Serrano Suñer asegura que él fue el principal defensor de trasladar la capitalidad y que su candidata favorita era Sevilla. ${ }^{49} \mathrm{Al}$ parecer, la decisión final de mantener la capitalidad de España en Madrid se fundamentó en la tradición imperial de la ciudad. $5^{\circ}$

Merece la pena reflexionar más sobre un proceso represor basado en la lógica de la justicia al revé, es decir, en el castigo de republicanos como rebeldes. No fue solo una represión de las derechas contra las izquierdas. Fue esto y mucho más. Cualquier servicio al Estado republicano, aunque hubiese sido forzado, significaría una condena. Por este motivo muchos quintacolumnistas fueron a la cárcel por su trabajo en pro de la Republica, aunque en realidad servían la causa franquista. Basta un ejemplo. En enero de 1940, el Consejo Supremo de Justicia Militar dictó sentencia contra el comandante Manuel Albarrán Ordóñez. Tras fracasar en su intento

46 ABC [Madrid], 28 mar. 1940.

47 Informaciones, 20 may. 1939.

48 Julius Ruiz, La justicia de Franco (Barcelona: RBA, 2012), 78-79.

49 Serrano Suñer, Entre el silencio, 247-248.

50 Santos Juliá et al., Madrid. Historia de una capital (Madrid: Alianza, 1994), 431. 
de escapar a la zona rebelde en el verano de 1936, Albarrán fue obligado a organizar las fuerzas republicanas en el frente de Somosierra durante un tiempo antes de ingeniárselas para ser relevado de su puesto por una baja por enfermedad (fingida) en noviembre de 1936. Tras participar en actividades quintacolumnistas a partir de ese momento, acabó siendo detenido por la policía republicana en octubre de 1937 y sentenciado a la pena capital, condena que posteriormente le fue conmutada. Liberado de una cárcel republicana el 28 de marzo de 1939, tuvo que comparecer ante un consejo de guerra el 8 de septiembre de 1939. Después de ser absuelto, su causa fue remitida por el auditor de guerra al Consejo Supremo de Justicia Militar por discrepancias con el veredicto. En una nueva sentencia que imponía a Albarrán una pena de dos años de prisión por «auxilio a la rebelión», el alto tribunal castrense recordaba al infortunado quintacolumnista que todo oficial de carrera «tenía el deber de llevar al sacrificio su vida antes que prestar servicio a los enemigos de la Patria».51

La consecuencia lógica de este tipo de criterio judicial fue la incoación de cientos de miles de expedientes judiciales militares. En Granada, por ejemplo, más de 60.000 causas fueron incoadas después de marzo de $1939.5^{22}$ Las cárceles estaban abarrotadas. En Madrid, había unos 50.000 reclusos a finales de diciembre de 1939, y 240.000 en toda España en octubre de 1940.53 Por lo tanto, la justicia militar franquista de posguerra fue brutal y cruel, basada en la farsa legal de la justicia al revés. ¿Pero refleja ello «un programa de exterminio», como sostiene Secundino Serrano? Como he dicho, las investigaciones locales no respaldan esa tesis. Bien al contrario, las sentencias de muerte siempre fueron una minoría. En Albacete, por ejemplo, Manuel Ortiz Heras estima que solo el tres por ciento de las condenas terminaron con la muerte del condenado. ${ }^{54}$ Incluso la ferocidad de los consejos de guerra se redujo con el paso del tiempo. El bienio

51 Archivo General de la Administración (Alcalá de Henares), Ministerio de Justicia (Fondo de Responsabilidades Políticas), 30.510.

52 Rafael Gil Bracero, «La justicia nacional y el Tribunal de Responsabilidades Políticas de Granada: las fuentes y primeras conclusiones», Justicia en guerra (Madrid: Ministerio de Justicia, 1990), 606.

53 Documentos inéditos para la historia del Generalísimo Franco (Madrid: Fundación Nacional Francisco Franco, 1992), vol. 2(i), 386-387.

54 Manuel Ortiz Heras, Violencia política en la II República y el primer franquismo (Madrid: Siglo XXI, 1996), 370-371. 
1939-1940 fue en el que se dieron el setenta por ciento de las ejecuciones en Madrid y en Levante, y el ochenta y cinco por ciento en Barcelona. ${ }^{55}$ Así pues, no se puede establecer una relación clara entre el declive de fusilamientos y una situación internacional cambiante. Algunos dicen que los franquistas terminaron los fusilamientos en masa para lavar la cara del régimen ante la derrota del Eje en la Segunda Guerra Mundial..$^{6}$ Es decir, se hubiese continuado el exterminio si no hubiese sido por la victoria de los Aliados. Pero es evidente que el proceso empezó cuando la Wehrmacht alemana aún dominaba el continente europeo; la ferocidad de la represión franquista claramente disminuyó antes de la victoria soviética en Stalingrado y de la Operación Torch en el invierno de 1942-1943, que cambiaron la situación estratégica de la guerra por completo.

Sin embargo, como hemos visto más arriba, no se aplicó únicamente la lógica de la justicia al revés en los consejos de guerra. El régimen franquista creó otras jurisdicciones especiales para castigar a los vencidos. Y también en esas esferas el fin de la guerra supuso una intensificación de los procesos represivos iniciados durante el conflicto. Tomemos como ejemplo la esfera de responsabilidades políticas. En septiembre de 1936, todas las organizaciones del Frente Popular fueron declaradas fuera de ley y se incautaron sus bienes. Según el preámbulo del decreto, el Frente Popular fue la culminación del antipatriotismo «que, bajo apariencia política, envenenó al pueblo» y culminó en la «absurda resistencia sostenida contra el movimiento nacional» a partir de julio de 1936.57 Apenas una semana después de la caída de Cataluña, en febrero de 1939, el régimen publicó la tristemente famosa Ley de responsabilidades políticas. Su artículo primero declaraba «la responsabilidad política de las personas, tanto jurídicas como físicas, que desde primero de octubre de mil novecientos treinta y cuatro y antes de dieciocho de julio de mil novecientos treinta y seis, contribuyeron a crear o a agravar la subversión de todo orden de que se hizo víctima a España y de aquellas otras que, a partir de la

55 Ruiz, «A Spanish Genocide», 177-178.

56 Véase, por ejemplo, Richards, Time of Silence, 223.

57 Boletín Oficial de la Junta de Defensa Nacional de España, 16 sept. 1936. 
segunda de dichas fechas, se hayan opuesto o se opongan al Movimiento Nacional con actos concretos o con pasividad grave»..$^{8}$

Esto es de nuevo la justicia al revés en su forma más extrema: actos pasivos desde la revolución de octubre de 1934, o sea dieciocho meses antes de la rebelión misma, bastaban para ser culpable. No fue la única novedad: el mismo mes, el régimen anunció las normas para la depuración de los funcionarios de la Administración estatal, esgrimiendo el mismo criterio que la Ley de responsabilidades políticas. ${ }^{59}$ Los franquistas ya habían purificado el magisterio con la siguiente justificación: «El hecho de que durante varias décadas el Magisterio en todos sus grados y cada vez con más raras excepciones haya estado influido y casi monopolizado por ideologías e instituciones disolventes, en abierta oposición con el genio y tradición nacional, hace preciso que [...] se lleve a cabo una revisión total y profunda en el personal de Instrucción Pública, [...] extirpando así de raíz esas falsas doctrinas que con sus apóstoles han sido los principales factores de la trágica situación a que fue llevada nuestra Patria». ${ }^{60}$

El resultado de todo esto fue el esperable: cientos de miles de expedientes. Unos 60.00o maestros y maestras de escuela tuvieron que demostrar su lealtad al régimen para que se les permitiera enseñar en la España de Franco. ${ }^{61}$ En el ámbito de responsabilidades políticas, más de 189.000 expedientes fueron incoados hasta septiembre de 1941, pero, como muchas de las investigaciones fueron colectivas, el número real de inculpados fue mayor. ${ }^{62}$ A pesar de ello, el celo represor del Nuevo Estado franquista superaba con mucho sus propias capacidades; el régimen no tenía los recursos necesarios para castigar a tanta gente. En ese mismo año empezó el proceso de liquidación de la represión masiva. Se aceleró el proceso de sobreseimiento de las causas militares y 47.000 penados salieron en libertad condicional en 1941. A finales de 1943, cuando el régimen decretó la libertad condicional a todos los penados salvo a aquellos culpables de

58 Boletín Oficial del Estado, 13 febr. 1939.

59 Boletín Oficial del Estado, 14 febr. 1939.

60 Boletín Oficial del Estado, 11 nov. 1936.

61 Francisco Morente Valero, La Escuela y el Estado Nuevo: la depuración del Magisterio Nacional (1936-1943). (Valladolid: Ámbito, 1997)

62 Archivo General de la Administración (Alcalá de Henares), Ministerio de la Presidencia, caja 4.022. DICTATORSHIPS \& DEMOCRACIES 8 (2020) - E-ISSN: 2564-8829 - PUNCTUM, UNIVERSITAT OBERTA DE CATALUNYA \& FUNDACIÓ CARLES PII SUNYER 
«crímenes de sangre», 134.00o ya habían salido de la cárcel. En febrero de 1952, solo había unos 800 condenados por crímenes de guerra en prisión. ${ }^{63}$ Del mismo modo, una reforma de la Ley de responsabilidades políticas de febrero de 1942 archivó la gran mayoría de las investigaciones. Finalmente, la ley quedó derogada a efectos prácticos por un decreto de abril de 1945, aunque solo se decretó «la prescripción de todos los delitos cometidos con anterioridad al 1 de abril de 1939» con ocasión del trigésimo aniversario de la victoria franquista. ${ }^{64}$

Para justificar públicamente un proceso tan masivo como el de la liquidación del legado penitenciario de la Guerra Civil, el régimen recurrió a los lemas católicos de la redención y la caridad. Los prisioneros puestos en libertad, habiendo expiado ya su pecado de apoyo a la República, estaban listos por fin para reintegrarse en la comunidad nacional. El preámbulo del decreto de 17 diciembre de 1943 que extendía la libertad condicional a los penados con sentencias de veinte años y un día, retrataba una «Patria» benevolente, «una gran familia regida en su espiritualidad por los más puros principios cristianos, [que] induce [al régimen] a extender generosamente los preceptos legales de perdón ... [y a] incorporar a la vida nacional y familiar un considerable número de españoles que inducidos por insensatas propagandas abandonaron los caminos del bien». ${ }^{65}$

La redención no fue solo la característica clave del proceso masivo de puesta en libertad condicional, sino de la política penitenciaria de los franquistas en general. Los penados podían reducir sus sentencias mediante el trabajo. Franco estableció el criterio del programa de la redención de penas por el trabajo por decreto en mayo de 1937. Basado en el principio de que se tiene el derecho y la obligación de trabajar, subyacente en la creación (unos días después) de los batallones de trabajo de prisioneros de guerra, el proyecto entró en vigor el 1 de enero de 1939. Los vencidos proporcionaron al Estado franquista y a la industria privada una fuente barata de mano de obra. Parte de los trabajos se realizaban en talleres instalados en las propias prisiones. El primero de los que se creó bajo los

63 Ruiz, La justicia de Franco, 174.

64 Ibíd., 234-240 \& Boletín Oficial del Estado, 1 abr. 1969.

65 Boletín Oficial del Estado, 20 dic. 1943. 
auspicios del programa fue inaugurado por el padre Pérez del Pulgar, director y avalador ideológico del Patronato Central para la Redención de las Penas por el Trabajo, en la Cárcel Central de Alcalá de Henares, en agosto de 1939. Como no podía ser de otro modo, los primeros productos allí fabricados fueron bancos de iglesia y 15.000 crucifijos de escuela. En septiembre de 1943 , había ya 800 presos redimiendo su pena en ese taller. ${ }^{66}$ No obstante, el trabajo realizado fuera de las cárceles fue mucho más importante. Sin duda, el ejemplo más famoso fue la obra privada (aunque bajo el control general del Estado) en Cuelgamuros, en las inmediaciones de El Escorial. Tres empresas privadas (San Román, Molán y Banús) se encargaron de la construcción del Valle de los Caídos, el monumento conmemorativo que Franco dedicó a los muertos de guerra; en 1943, trabajaban allí 250 reclusos. ${ }^{67}$

Sin embargo, un grupo fue siempre excluido de los programas franquistas de redención: los masones. De hecho, la represión de la masonería se intensificó durante los años cuarenta. Las opiniones de Franco sobre ellos son bien conocidas. Según su versión de la historia, eran responsables de todos los males de la patria, tal y como rezaba el preámbulo de la Ley sobre represión de la masoneria y el comunismo de marzo de 1940: «Acaso ningún factor, entre los muchos que han contribuido a la decadencia de España, influyó tan perniciosamente en la misma y frustró con tanta frecuencia las saludables reacciones populares y el heroísmo de nuestras Armas, como las sociedades secretas de todo orden y las fuerzas internacionales de índole clandestina. Entre las primeras, ocupa el puesto más principal la masonería». ${ }^{6}$

Hay que subrayar que, a pesar de su título, la ley de marzo de 1940 estaba dirigida casi exclusivamente contra los masones. Entre los casi 700 madrileños condenados por su Tribunal Especial antes de 1945, por ejemplo, el 96\% eran masones; y de las más de 2.000 sentencias emitidas por el Tribunal Especial contra exiliados hasta la derogación de la ley en 1963,

66 José Manuel Sabín, Prisión y muerte en la España de postguerra (Madrid: Anaya \& Muchnik, 1996), 169-197.

67 Daniel Sueiro, La verdadera historia del Valle de los Caídos (Madrid: Sedmay,1976).

68 Boletín Oficial del Estado, 2 mar. 1940. 
el 98\% fueron de condenas por masonería y solo en doce casos por comunismo. Como en el de Juan Negrin, que ni siquiera era militante del PCE. ${ }^{69}$

Es también interesante observar que, a diferencia de los mecanismos institucionales de las otras jurisdicciones de la represión, la ley antimasónica se mantuvo sin reformas hasta su derogación en 1963. Más aún, la persecución se intensificó durante los años de aislamiento internacional de España después de la Segunda Guerra Mundial. Entre las casi 27.000 causas abiertas por el Tribunal Especial entre 1941 y 1953, el 58\% tuvieron lugar después de $1946 .^{70}$ Estos fueron los años de los artículos de Jakim Boor, o sea del propio Franco, en Arriba denunciando los llamados «manejos turbios de la masonería internacional», dirigidos por el presidente estadounidense y gran maestre Harry S. Truman. Como el caudillo escribió el 9 de agosto de 1949, «al ocupar la Presidencia, por la muerte del anterior Presidente [Roosevelt en 1945], Mr. Truman, de gran abolengo masónico, se acerca a aquella meta deseada con la elevación de éste al más alto grado de la masonería americana». Entonces aprovecha «la masonería el ascenso de los Estados Unidos al primer puesto rector del Occidente, como consecuencia de la victoria [en 1945]... y como inmediata consecuencia de la ofensiva a España». ${ }^{71}$

En conclusión, ¿cómo se puede explicar la represión durante el primer franquismo? Es patente, como demuestran las instrucciones de Mola en 1936, que los rebeldes estaban dispuestos a utilizar una violencia extrema para salvar España. Pero eso no significa que los fusilamientos obedecieran a planes de exterminio. El terror en la España rebelde, como en la España leal, fue consecuencia del fracaso de la rebelión militar y de la fractura del poder. Como hemos visto, se produjo una caída relativa de ejecuciones después de la institucionalización de la represión en el invierno de 1936-1937. Es decir, mientras el objetivo general de la represión —el castigo de la anti-España — fue constante, la manera de conseguir esta meta cambió con la fundación del Nuevo Estado. El final de la guerra no cambió mucho las cosas en este sentido. El régimen estableció nuevas ju-

69 Ruiz, La justicia, 299-306.

70 Centro Documental de la Memoria Histórica (Salamanca), TERMC, caja 1.257.

71 Jakim Boor [Francisco Franco], «Alta masonería», Arriba, 9 ag. 1949, reproducido en http:// www.conoze.com/doc.php?doc $=5345$. 
risdicciones represivas en los últimos meses de la guerra que empezaron su labor después de la derrota de la República, como la Ley de responsabilidades políticas de febrero de 1939. A pesar de ello, el régimen no disponía de la capacidad para castigar a tantos republicanos, y miles de los vencidos salieron de las cárceles a partir de 1941. Esta liquidación de la represión masiva no tenía nada que ver con la reconciliación; el régimen no cesaba de perseguir a la oposición antifranquista con saña y ferocidad. El antifranquismo continuaba siendo sinónimo de criminalidad; o según el decreto de abril de 1947, de bandidaje y terrorismo. ${ }^{72}$ El discurso franquista mantuvo la división entre españoles y antiespañoles, que perduraría hasta la muerte del dictador. Pero la liquidación de la represión masiva es significativa. En ello encontramos una explicación de la longevidad del régimen: la capacidad de adaptarse a las circunstancias sin repudiar formalmente su ideología. 